\title{
Airway management after upper cervical spine injury: what have we learned?
}

\author{
[La prise en charge des voies aériennes supérieures à la suite d'une lésion de la \\ colonne cervicale : que savons-nous de plus ?]
}

Edward Crosby MD

Purpose: Survival after atlanto-axial-occipital ligamentous injury is uncommon and experience with the immediate clinical management of these patients is similarly low. There has been considerable work published recently with respect to airway management in similar patients and a review of this material was undertaken.

Methods: Medline searches were performed to seek out the English language literature using the key words and phrases: cervical spinal injury; atlanto-occipital dislocation; atlanto-occipital disarticulation; and airway management after spinal injury. The titles were culled for materials relevant particularly to upper cervical spinal injury, these were obtained and reviewed. The bibliographies of these articles were searched to ensure that the review would be complete.

Relevant findings: The majority of cervical spinal movement occurring during direct laryngoscopy is concentrated in the upper cervical spine. The magnitude of movement during airway management rarely exceeds the physiological limits of the spine. Movement is reduced by in-line immobilization but traction forces cause clinically important distraction and should be avoided. Indirect techniques for tracheal intubation cause less cervical movement than does the direct laryngoscope. Survival after severe upper ligamentous injury is uncommon but intact survival occurs. Missed diagnosis is common and associated with a high incidence of severe secondary injury. Failure to immobilize the spine is deemed to be the most relevant factor in secondary injury.

Conclusions: Patients who survive severe upper cervical ligamentous injury and present to hospital are uncommon. However, of those who do, both intact survival and survival with limited neurological sequelae do occur. Meticulous airway care with maintenance of alignment and provision of continuous cervical immobilization are an integral component of care in these patients.
Objectif : Il est rare qu'on survive à une blessure ligamentaire atlanto-axoïdienne-occipitale et le traitement clinique immédiat des patients qui en sont victimes est peu connu. De nombreuses publications récentes traitent de la prise en charge des voies aériennes dans des cas semblables. Une revue de ce matériel a donc été entreprise.

Méthode : Une recherche d'articles de langue anglaise a été faite dans Medline à partir des mots clefs et expressions : cervical spinal injury ; atlanto-occipital dislocation ; atlanto-occipital disarticulation et airway management after spinal injury. Les articles retenus et revus traitaient particulièrement de lésions de la colonne cervicale supérieure. La revue a été complétée par l'examen des bibliographies de ces articles.

Constatations pertinentes : La majorité des mouvements de la colonne cervicale qui se produisent pendant la laryngoscopie directe mettent en jeu la colonne cervicale supérieure. L'amplitude du mouvement pendant la prise en charge des voies aériennes dépasse rarement les limites physiologiques de la colonne. Le mouvement est réduit par l'immobilisation synchronisée, mais les forces de traction causent d'importantes distractions cliniques et devraient être évitées. Les techniques indirectes d'intubation trachéale causent moins de mouvements cervicaux que la laryngoscopie directe. La survie à la suite d'une sévère lésion ligamentaire supérieure est rare, mais possible sans séquelle. II est fréquent de manquer le diagnostic, ce qui est associé à une incidence élevée de blessure secondaire sérieuse. Le défaut d'immobiliser la colonne est considéré comme le facteur le plus significatif de blessure secondaire.

Conclusion : Peu de patients survivent à une importante lésion ligamentaire cervicale supérieure. Cependant, parmi ceux qui se présentent avec cette blessure, certains survivent sans séquelles et d'autres subissent des limitations neurologiques. La prise en charge des voies aériennes de ces patients doit être minutieuse et comporter le maintien de l'alignement de la colonne cervicale par une immobilisation continue.

From the Department of Anesthesiology, University of Ottawa, Ottawa, Ontario, Canada.

Address correspondence to: Dr. Edward Crosby, Department of Anesthesiology, Ottawa Hospital, General Site, Room 2600, Tower 3 ,

501 Smyth Road, Ottawa, Ontario K1H 8L6, Canada. Phone: 613-737-8187; Fax: 613-737-8189; E-mail: ecrosby@magma.ca Accepted for publication January 22, 2002.

Revision accepted May 27, 2002. 
A 30-yr-old man presented to our institution after a single-vehicle motorcycle accident. He was retrieved by the ambulance service and brought to hospital, with his spine appropriately immobilized. It was observed during transit that he was making no respiratory efforts, despite near normal hemodynamic parameters being measured. Ventilation was provided in-transit with a mask and bag and this respiratory support was continued after arrival in the Emergency Room. An injury survey revealed bilateral pneumothoraces and a fractured mandible. A lateral radiograph of his cervical spine revealed a distraction of the atlanto-occipital joint of approximately $1 \mathrm{~cm}$.(Figure 1) The anesthesiology service was called urgently to assess and manage the airway. There was obvious facial trauma with a bloodied airway and missing teeth: it was not apparent as to whether the dental losses were recent or remote. A decision was made to proceed with direct laryngoscopy for assessment of the airway for foreign bodies, followed by tracheal intubation under direct vision. The anterior portion of the Philadelphia collar was removed and replaced by manual in-line immobilization (MILI) applied without traction forces. Mask bag ventilation was continued and fentanyl $100 \mu \mathrm{g} \cdot \mathrm{kg}^{-1}$ and lidocaine $80 \mathrm{mg}\left(\mathrm{l} \mathrm{mg} \cdot \mathrm{kg}^{-1}\right)$ were administered intravenously. No cricoid pressure was applied. Direct laryngoscopy was carried out, revealing no obvious foreign bodies. The larynx was sprayed with lidocaine and the trachea was intubated using an endotracheal tube mounted on a lighted stylet. The cuff was inflated, the position confirmed, and the tube secured.

He was transferred to the intensive care unit where he had a halo fixator placed by the neurosurgical service. Initially, he remained unresponsive, intubated, and ventilated but after $24 \mathrm{hr}$, he began to show evidence of neurological improvement. Initially, this was evidenced by withdrawal of both legs to command. $\mathrm{He}$ also regained spontaneous respiration but remained on a ventilator for airway protection and airway pressure support. His condition continued to improve over the next $48 \mathrm{hr}$ and, at his family's request, he was transferred to their home city for definitive treatment of posterior occipito-cervical fusion. At that time, his neurological condition had continued to improve although residual quadraparesis remained.

Survival after upper cervical injuries such as that experienced by this patient is uncommon and consequently, experience with the immediate clinical management of these patients is similarly low. However, there has been considerable work published with respect to airway management in patients with cervical injury, particularly in the last decade, and a review of

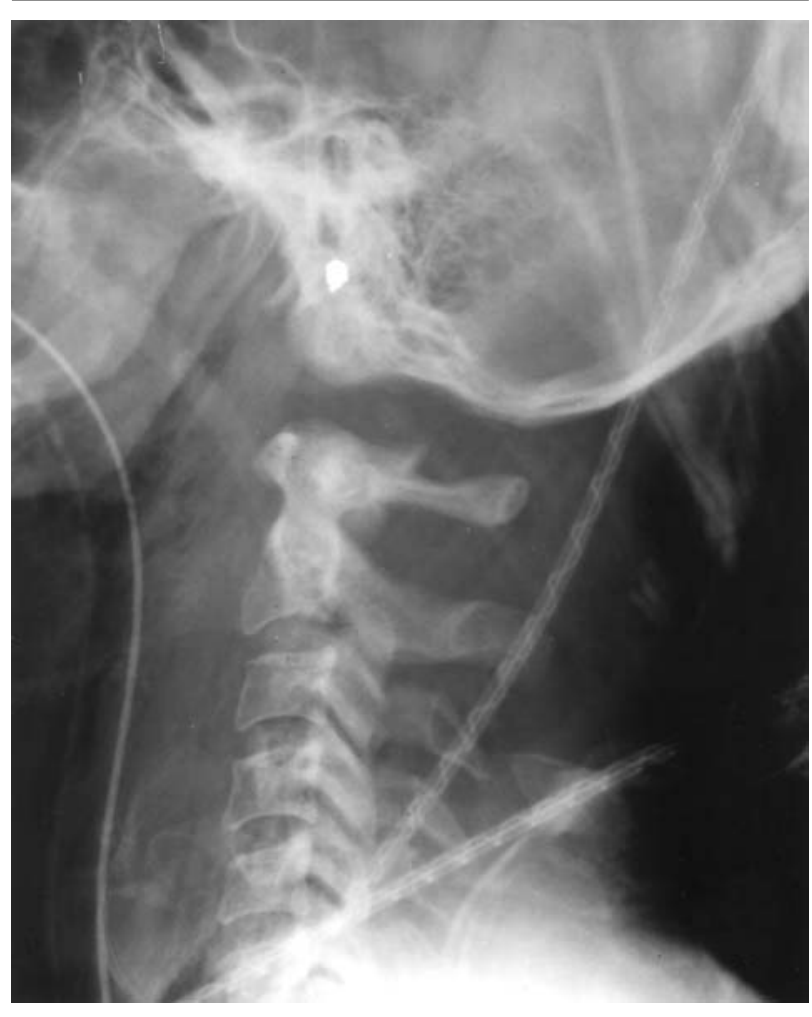

FIGURE I Lateral cervical spine radiograph demonstrating features of both a distraction (type II) and anterior translation (type I) atlanto-occipital dislocation.

this material was undertaken to help shed light on management issues in this particular scenario. Medline searches were performed to seek out the English language literature using the key words and phrases: cervical spinal injury; atlanto-occipital dislocation; atlanto-occipital disarticulation; and airway management after spinal injury. Titles were culled for materials relevant particularly to upper cervical spinal injury and these were obtained and reviewed. The bibliographies of articles of special interest were hand searched to ensure that the review of the topic would be complete.

\section{Results of literature review}

Anatomy of the upper cervical spine

The upper two and lower five cervical vertebrae differ both anatomically and functionally and the cervical spine is conventionally divided in the upper cervical spine, comprising the atlanto-axial-occipital complex (occiput, $\mathrm{Cl}$ and $\mathrm{C} 2$ ) and the lower or subaxial spine (C3-7 inclusive). The following discussion will deal primarily with the upper cervical spine.

The anatomy of the atlanto-axial-occipital joint is complex (Figure 2). The first cervical vertebra, the atlas 


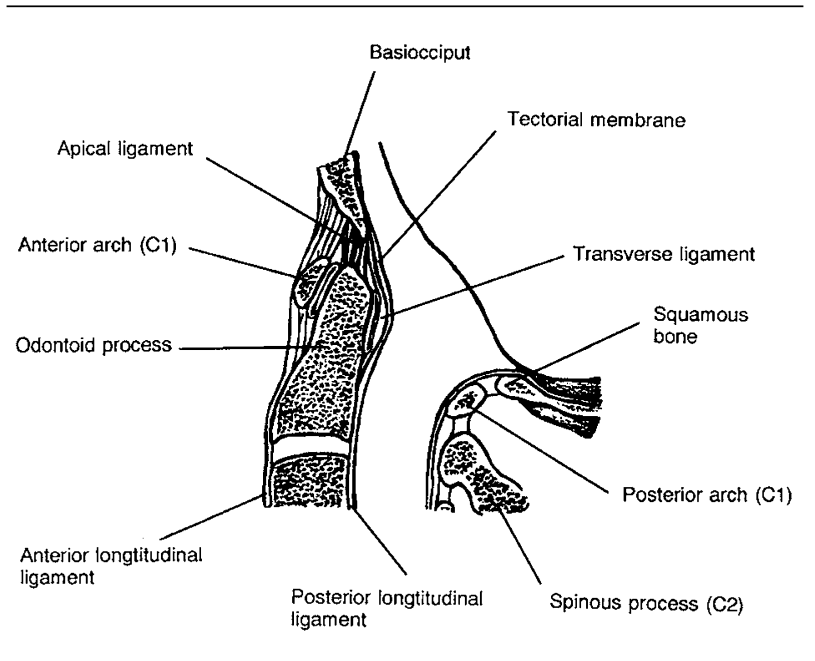

FIGURE 2 The anatomy of the occipito-atlanto-axial articulation.

$(\mathrm{Cl})$, has thick anterior and posterior arches that blend laterally into large masses. The occipital condyles of the skull articulate with the superior aspects of these lateral masses. The flatter inferior surfaces transmit the weight of the skull onto the superior facet joints of the axis $(\mathrm{C} 2)$, the second cervical vertebra. On the atlas $(\mathrm{Cl})$, arising bilaterally and projecting inwards, two bony tubercles provide insertion points for the transverse ligament. Laterally placed and on the superior surface of the axis $(\mathrm{C} 2)$ are circular facets that articulate with the lateral masses of the atlas. The body of the axis $(\mathrm{C} 2)$ extends upwards to form the odontoid process which is held in place by the transverse ligament of the atlas (Cl). Alar and apical ligaments fan upwards from the odontoid process to insert on the anterior margins of the foramen magnum. The spinous process of the axis (C2) is large and heavy, allowing for muscle and ligament insertion.

The anterior and posterior longitudinal ligaments extend the length of the cervical spine. The anterior ligament inserts on the intervertebral discs and adjacent vertebrae and ascends along the anterior surface of the spine. It terminates over the anterior arch of the atlas, forming the anterior atlanto-occipital ligament which inserts on the base of the skull. The posterior ligament courses upwards along the dorsal surface of the vertebral bodies, fans over the body of the axis and the odontoid process and terminates as the tectorial membrane which inserts into the basiocciput of the skull. The ligamentum flavum connects the adjacent laminae and it is often a tenuous structure in the cervical region. Coursing between spinous processes are the interspinous and supraspinous ligaments. The

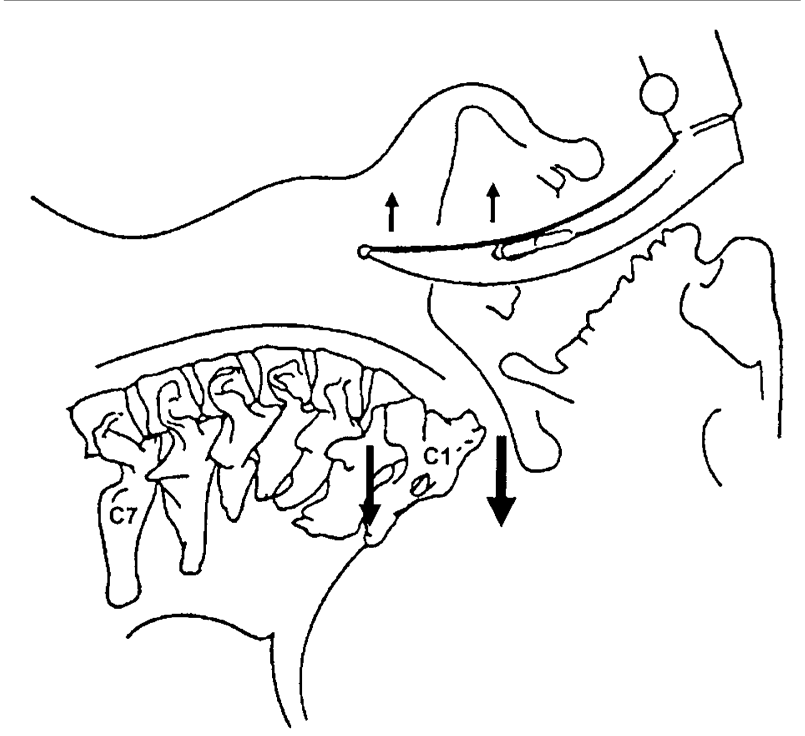

FIGURE 3 Cervical motion during laryngoscopy and intubation. Elevation of the laryngoscope blade results in extension of atlanto-occipital and atlanto-axial joints and minimal displacement of the subaxial spine.

supraspinous ligament is renamed the ligamentum nuchae in the cervical region.

The space available for the spinal cord (SAC) is defined as the luminal diameter of the spinal canal measured in the antero-posterior plane, at the $\mathrm{Cl}$ level, that is not occupied by the odontoid process. In the normal spine, the SAC is approximately $20 \mathrm{~mm} .{ }^{1}$ Although it is larger at $\mathrm{Cl}$ than it is in the subaxial spine, the cord too is larger at this level. Steel has defined a rule of thirds. ${ }^{2}$ The area of the vertebral canal is divided into one-third odontoid, one-third cord and one-third "space". The SAC at the Cl level is composed of cord and space and the space allows for some degree of canal encroachment before the cord is jeopardized. The space component affords some protection to the cord in the event that the canal is compromised by bone elements: cord compression does not typically occur until the SAC has been reduced to 14 mm or less. ${ }^{1}$

\section{Movement in the upper cervical spine}

Flexion-extension occurs in the upper cervical spine at both the atlanto-occipital and atlanto-axial articulations with the majority provided by the atlanto-occipital joint. ${ }^{3}$ Flexion at the atlanto-occipital articulation is limited by contact between the odontoid process and the anterior border of the foramen magnum. 


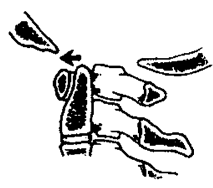

Type 1

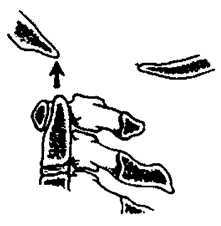

Type II

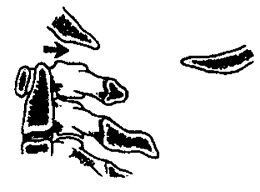

Type III
FIGURE 4 Traynelis' classification of atlanto-occipital dislocations.

Extension is limited by the tectorial membrane and posterior elements, predominantly at the $\mathrm{Cl}-\mathrm{C} 2$ level. The paired alar ligaments control lateral bending and axial rotation; the left alar ligaments limit rotation to the right and the right alar ligament limits rotation to the left. The bony architecture of the atlanto-occipital joint lends little stability to the articulation. It is the complex interaction of the two groups of ligaments spanning the joint that provides the structural integrity. The tectorial membrane and the paired alar ligaments are primary stabilizers of the cranio-vertebral junction and disruption of these cause translational instability at the atlanto-occipital junction.

White et al. have defined stability as the ability of the spine to limit its pattern of displacement under physiologic loads so as not to allow damage or irritation of the spinal cord or nerve roots. ${ }^{4}$ They have also identified the upper limit of spinal displacement and that which is beyond the physiologic range. ${ }^{5}$ Although much of this work was carried out on the subaxial spine, knowledge of this data is useful when attempting to interpret the findings of studies which have measured spinal movements during airway maneuvers. White concluded that a normal adult spine would not permit horizontal motion greater than $2.7 \mathrm{~mm}$ between vertebrae. Therefore, if horizontal displacements exceeding 3.5 $\mathrm{mm}$ (corrected for $x$-ray magnification) or $20 \%$ of the vertebral body width, is found on lateral $x$-rays of the neck in an acutely injured adult, this motion is abnormal and the spine is unstable. With respect to angular displacement, the upper limit of physiologic angular displacement of a vertebral body compared with adjacent vertebrae was $11^{\circ}$ (it is not affected by $x$-ray magnification). If there is angulation of the vertebra in question that is $11^{\circ}$ or greater off the angulation of either normal adjacent vertebra (or in an unstable spine model, from its original resting position) then the spine is unstable at the site of the excessively rotated vertebra.
Presumably, we can conclude that if movements of these or greater magnitude are measured during procedures, that these procedures have the potential to injure neurological elements. If the resultant movements are significantly less than those noted above, the procedures probably represent little risk to the underlying neural elements.

\section{Spinal movement during direct laryngoscopy and intu- bation}

Sawin $e t$ al. determined the nature, extent and distribution of segmental cervical motion produced by direct laryngoscopy and orotracheal intubation in human subjects without cervical abnormality. ${ }^{6}$ Ten patients underwent laryngoscopy using a \#3 Macintosh blade while under general anesthesia and neuromuscular blockade. Cervical motion was recorded with continuous lateral fluoroscopy and segmental motion, from the occiput through C5, was calculated for both laryngoscopy and intubation. During laryngoscope blade insertion, minimal displacement of the skull base and cervical vertebral bodies was observed. However, elevation of the laryngoscope blade to achieve visualization of the larynx created superior rotation of the occiput and $\mathrm{Cl}$ in the sagittal plane, and mild inferior rotation of C3-C5. C2 maintained near-neutral posture. This pattern of displacement resulted in extension at each motion segment, with the most significant motion produced at the atlanto-occipital and atlanto-axial joints (mean $6.8^{\circ}$ and $4.7^{\circ}$, respectively; Figure 3 ). Intubation created slight additional superior rotation at the occiput and $\mathrm{Cl}$, without substantial alteration in the postures of C3-C5. After removal of the laryngoscope, the position trended toward baseline at all levels, although exact neutral posture was not regained.

Horton conducted a similar experiment in volunteers under topical anesthesia only. ${ }^{7}$ After application of topical anesthesia, subjects were placed supine, in the sniffing position. They then underwent direct laryngoscopy with a curved Macintosh blade and, at full glottic exposure, a lateral $x$-ray of the head and neck was performed. Horton concluded after review of the $x$-ray data that, the position of the lower cervical spine remained static during laryngoscopy but that there was progressively increasing extension from $\mathrm{C} 4$ to the base of the skull and that extension in the atlanto-axial-occcipital complex was near maximal. There is agreement between Sawin and Horton, that during laryngoscopy in both awake and asleep subjects, most of the cervical motion is produced at the atlanto-occipital and atlanto-axial joints and that the subaxial cervical segments (C4 and below) are displaced only minimally. 
Spinal movement during laryngoscopy in models of the injured cervical spine

Donaldson et al. studied the motion that occurred during intubation in a cadaver model with an unstable Cl-2 segment. ${ }^{8}$ Flexion-extension, chin lift, jaw thrust, blind nasal intubation, crash oral intubation (direct laryngoscopy and oral intubation as would be performed in a emergency situation in the emergency department), and gentle oral intubation (using extreme caution to diminish cranio-cervical motion) were initially performed on cadavers with intact spines. The head was stabilized during intubation procedures but not during maximum flexion and extension maneuvers. Once the maneuvers were complete and recorded on the intact specimen, an unstable segment was created at $\mathrm{Cl}-2$ by producing an odontoid fracture with an osteotome. Airway maneuvers were then repeated and angulation, distraction and the space available for the cord were all measured. The SAC narrowed $1.49 \mathrm{~mm}$ on maximum flexion and extension in the intact cervical spine and $6.06 \mathrm{~mm}$ in the unstable spine. Chin lift $(\mathrm{lmm})$ and jaw thrust $(2.5 \mathrm{~mm})$ had the greatest effect in narrowing the SAC. Oral intubation and nasal intubation were similar in the amounts of SAC reduction that they created $(1.6 \mathrm{~mm})$. In the unstable cadaver chin lift, jaw thrust, and crash intubation resulted in similar distraction at the injured level ( $1-2 \mathrm{~mm})$. Distraction measurements during gentle oral intubation and nasal intubation were both less than $1 \mathrm{~mm}$. During intubation maneuvers, chin lift and jaw thrust created angulations simi$\operatorname{lar}\left(4^{\circ}-5^{\circ}\right)$ to those of the oral intubation techniques but nasal intubation caused less $\left(2.5^{\circ}\right)$. There were no significant movements seen at the $\mathrm{Cl}-2$ region when cricoid pressure was applied in either the stable or unstable model. Donaldson concluded that pre-intubation maneuvers produced more narrowing of the SAC than did the actual intubation techniques, that nasal techniques resulted in similar SAC narrowing to that of the oral techniques, and that application of cricoid pressure produced no significant movement at a Cl-2 site of injury. Aprahamian et al. concluded similarly that pre-intubation movements (chin lift, jaw thrust) caused as much or movement $(5 \mathrm{~mm})$ at the site of injury (posteriorly destabilized C5-6) as oral or nasal intubation. ${ }^{9}$

Lennarson et al. examined the efficacy of commonly used stabilization techniques in limiting spinal motion in a model of the injured spine. ${ }^{10}$ Lennarson's model involved the creation of a posterior ligamentous injury at the C5 level. Consistent with the findings of Sawin, Horton and Donaldson, the predominant motion at all levels during laryngoscopy and intubation measured in the intact spine was extension. The greatest degree of motion occurred at the atlanto-occipital junction, followed by the $\mathrm{Cl}-2$ junction, with progressively less motion at each more caudal level. After destabilization, only traction (using Gardener-Wells tongs) but not immobilization limited motion at the $\mathrm{Oc}-\mathrm{Cl}$ junction. Neither traction nor immobilization limited motion at the destabilized C5 level. Lennarson et al. conducted a similar experiment assessing the efficacy of immobilization maneuvers in the setting of complete segmental instability at the C4-5 level. ${ }^{11}$ Although the injury in Lennarson's model is at a lower level than seen in our patient, the degree of injury (total ligamentous disruption) is similar. Angular rotation, subluxation, and distraction were all measured at the injured level during the application of traction, MILI and without stabilization. Lennarson concluded that, in the setting of complete ligamentous instability, that traction effected far too much distraction at the site of injury. MILI, despite allowing some subluxation, permitted oral tracheal intubation while allowing cervical movements that were well within the physiological limits.

\section{Upper cervical spinal movement and laryngeal mask airways (LMA)}

Kihara et al. quantified the extent and distribution of segmental cervical movement produced by the intubating laryngeal mask (ILM) during manual in-line stabilization in 20 anesthetized patients with cervical pathology undergoing cervical spine surgery. ${ }^{12}$ The ILM was inserted with the head and neck in the neutral position and intubation was facilitated by trans-illumination of the neck with a lightwand. Spinal movement during ILM maneuvers was in the opposite direction to that seen with laryngoscopy, predominantly flexion. During ILM insertion, segmental levels C5 and above were flexed by less than $2^{\circ}$. During intubation, segmental levels $\mathrm{C} 4$ and above were flexed by $3^{\circ}$ or less, and during ILM removal, levels C3 and above were flexed by an average of $1^{\circ}$. During insertion and intubation $\mathrm{C} 2-5$ were displaced posteriorly by $1 \mathrm{~mm}$ or less but during removal, there were no changes.

Keller et al. measured the pressures exerted by the standard LMA and the ILM airway against the cervical vertebrae during insertion, intubation, and maneuvers commonly used to facilitate intubation. ${ }^{13}$ Keller also determined the effect of these pressures on cervical spine movement. Three micro-chip pressure sensors were implanted into the pharyngeal surface at $\mathrm{C} 2-3$ in 20 cadavers without cervical abnormality. The size 5 ILM and LMA were inserted in random order into each cadaver with the head and neck in the neutral position. 
Maximal cervical pressures (CPmax) were recorded for both devices during insertion, cuff inflation (from 0-40 $\mathrm{mL}$ ) and with the intracuff pressure (ICP) at $60 \mathrm{~cm}$ $\mathrm{H}_{2} \mathrm{O}$. In five additional matched cadavers, the effect of these pressures on the posterior displacement of $\mathrm{C} 3$ was assessed. CPmax for the LMA and ILM was similar during insertion (224 vs $273 \mathrm{~cm} \mathrm{H} O$ ). For the ILM, CPmax increased during handle depression $(394 \mathrm{~cm}$ $\left.\mathrm{H}_{2} \mathrm{O}\right)$ and partial withdrawal/reinsertion $(265 \mathrm{~cm}$ $\left.\mathrm{H}_{2} \mathrm{O}\right)$ but decreased during handle elevation $(6 \mathrm{~cm}$ $\mathrm{H}_{2} \mathrm{O}$ ). CPmax was higher for the ILM than the LMA over the inflation range (96 vs $15 \mathrm{~cm} \mathrm{H}_{2} \mathrm{O}$ ) and with the ICP at $60 \mathrm{~cm} \mathrm{H}_{2} \mathrm{O}\left(95\right.$ vs $\left.10 \mathrm{~cm} \mathrm{H}_{2} \mathrm{O}\right)$. The mean posterior displacement of $\mathrm{C} 3$ was $0.8 \mathrm{~mm}$ at $100 \mathrm{~cm}$ $\mathrm{H}_{2} \mathrm{O}$ and $2.8 \mathrm{~mm}$ at $400 \mathrm{~cm} \mathrm{H}_{2} \mathrm{O}$. Keller concluded that laryngeal mask devices exert high pressures against the upper cervical vertebrae during insertion, inflation and while in situ and that these pressures can produce posterior displacement of the upper cervical C-spine.

\section{Incidence, mechanism and consequences of atlanto- occipital dislocation (AOD)}

The first report of traumatic AOD was attributed to Blackwood in 1908. ${ }^{14}$ His patient survived $34 \mathrm{hr}$ after a fall. At autopsy, the upper spinal cord was found to be compressed between the posterior rim of the foramen magnum and the posterior surface of the dens. Since that time, and more frequently as of late, there have been a limited number of case reports and case series describing survivors of this usually fatal injury.

The incidence of traumatic AOD has not been precisely determined. Postmortem studies of fatal traffic accidents have been performed by a number of investigators. Alker et al. found radiographic evidence of cervical spine injuries in $24 \%$ of 312 victims, with one quarter of these injuries (nine patients, $6 \%$ of total) occurring at the cranio-cervical junction. ${ }^{15}$ Bucholz et al. also studied postmortem radiographs of 112 victims and found the incidence of cervical spine injuries to be $24 \%$, with nine patients ( $8 \%$ of total) having AOD. ${ }^{16}$ Davis et al. reported five cases of disruption of the $\mathrm{AO}$ joint in postmortem radiographic studies of the head and spine among 50 consecutive deaths from acute trauma. ${ }^{17}$ In the majority of the cases from these series, the injury was immediately fatal. Autopsy evaluation after such injuries has demonstrated direct mechanical injury of the lower brainstem and upper cervical spinal cord, usually consisting of transection of the cord, cord laceration with incomplete tear of the spinal cord, or spinal cord contusion. Chiu et al. estimated the incidence of ligamentous spinal injuries, including AOD in 14,577 survivors of blunt trauma admissions admitted to the Baltimore Shock Trauma
Center in the years 1996-98. ${ }^{18}$ The overall incidence of cervical spine injury was $4.2 \%(614$ of 14,577$)$ and the incidence of ligamentous cervical spine injuries including AOD was $0.6 \%$ (87 of 14,577). Thus, predominantly or exclusively ligamentous cervical injuries are not nearly as common in survivors of blunt trauma as they are in non-survivors.

The mechanism of AOD remains controversial and, although a variety of forces have been implicated, hyperextension, rotation, and distraction are probably the most important mechanisms of injury. Most AOD are caused by high-velocity accidents. Werne concluded that dislocation of the atlanto-occipital joint was possible only after severance of the tectorial membrane, and the paired alar ligaments. ${ }^{19}$ Considerable force is necessary to disrupt the extensive ligamentous complex of the cranio-vertebral junction. As a result of these extreme forces, the spinal cord will usually sustain such devastating injury as to result in immediate death. The high frequency of submental lacerations, mandibular fractures (as in our patient), and lacerations to the posterior pharyngeal wall emphasize the role of hyperextension in these injuries. ${ }^{16}$

Children appear to be more susceptible to sustaining AOD than adults. ${ }^{16}$ The child's relatively larger head size, more horizontally oriented-AO joint, smaller occipital condyles, and weaker supporting ligaments all contribute to this increased vulnerability. Injuries to the cervical spine also occur more frequently in automobile-pedestrian accidents than in collision accidents, and children are involved in automobile-pedestrian accidents more often than adults. ${ }^{16}$ Therefore, children not only possess a less stable anatomic configuration of their cranio-cervical junction, but also appear to be more predisposed to the most common inciting accident than adults. Recent reports have also noted the potential for AOD in children and small unrestrained adults after airbag inflation. ${ }^{20}$

Survivors of AOD obviously do not sustain the same severity of direct cord injury as do non-survivors. Neurological deficits in survivors are also attributed, at least in part, to the potentially reversible vascular consequences of the injuring forces. The neurologic deficits found in many survivors with AOD are more consistent with vascular insufficiency of the brainstem and cord than with direct mechanical compression or laceration of the brainstem and cord. ${ }^{14}$ Following AOD, the carotid and vertebral arteries may be directly compressed by bony structures, or may be forcefully stretched, resulting in vasospasm or intimal tear with dissection or thrombosis. Forceful rotation of the head may cause vertebral artery compression and vertebral artery thrombosis. If compression is brief ( 15 
min), reversible changes of ischemia may occur in the upper spinal cord. ${ }^{14}$ If ischemia persists, arterial thrombosis and severe permanent spinal cord injury result. Gabrielsen and Maxwell were the first to demonstrate vertebral artery injury in a survivor of AOD. ${ }^{21}$ Subsequently, Evarts reported a survivor of AOD with angiographic narrowing of the left vertebral artery at the atlanto-occipital level. ${ }^{22}$ Initially, the arterial injury was believed to be a minor associated injury that did not contribute to the neurologic dysfunction. However, Powers et al. reported a survivor of AOD in whom cerebral angiography demonstrated severe vasospasm of the internal carotid, middle cerebral, vertebral basilar arteries. ${ }^{23}$ The vasospasm responded to therapy with an improvement in the neurological deficits.

Cranio-cervical junction subarachnoid hemorrhage (SAH) after fatal blunt upper cervical trauma has also been described. ${ }^{24}$ Hyperextension may tear medullary branches from the vertebral artery, which is tethered at its dural entry above the $\mathrm{Cl}$ ring. The common association of cranio-cervical junction SAH with traumatic AOD has been reported in case series and reports of both fatal and nonfatal AOD. The association seems sufficiently strong that computed tomography (CT) identification of infra-tentorial SAH in the setting of non-diagnostic plain cervical radiographs should prompt evaluation of the atlanto-occipital joints.

\section{Presentation and clinical aspects of $A O D$}

Survival after traumatic AOD has become reportedly more common during the last two decades. Przybylski et al. collected the case reports of 79 survivors and Ferrera and Bartfield collected the reports of 70 victims with initial survival. ${ }^{24,25}$ Patients with AOD may exhibit a wide spectrum of neurologic deficits on presentation. In Przybylski's series, 14 (18\%) were neurologically normal, $8(10 \%)$ had isolated cranial nerve deficits, $27(34 \%)$ had unilateral limb deficits, and 30 (38\%) had quadriparesis or quadriplegia. ${ }^{24}$ Brain stem insults secondary to mechanical disruption, ischemia, or contusion may develop, leading to respiratory depression or arrest, cardiac arrhythmias, and decerebrate posturing. The caudad six pairs of cranial nerves are often impacted, with the abducens nerve (cranial nerve VI) being most commonly injured. ${ }^{24}$ Neurologic dysfunction of the extremities is often manifested by spasticity, sensory deficits, and motor paralysis, although hemiparesis appears to be the most common pattern. These deficits may improve after reestablishment of the cranio-vertebral alignment, presumably as a result of an improvement in the vascular supply.

Patients presenting with AOD have frequently also sustained a major head injury. At times, it is difficult to differentiate whether the neurologic findings are due to head injury or to local lower brain stem injury. Some deficits, however, are seen more characteristic of AOD than intracranial pathology. Brain stem injury explains the high incidence of bradycardia, asystole, and agonal respirations seen after AOD. Motor deficits are also frequently asymmetrical, such as hemiparesis or decortication on one side and decerebration on the opposite side. Asymmetrical motor findings often cannot be attributed to a cerebral injury but can be due to rotary subluxation of the $\mathrm{AO}$ joint or a brainstem vascular injury.

Lateral cervical spine plain radiographs are the initial studies used to make the diagnosis of AOD. The diagnosis is commonly missed after interpretation of plain radiographs and Przybylski noted that these were initially interpreted as non-diagnostic in 19 of 50 children $(38 \%)$ and in 17 of 29 adults $(59 \%) .{ }^{24}$ Unfortunately, $36 \%$ of patients with undiagnosed AOD experienced neurologic deterioration due to inadequate cervical immobilization. This rate of neurological deterioration is worse than the $10.5 \%$ incidence seen with undiagnosed lower cervical injury reported by Reid $e t a l .{ }^{26}$ but similar to the $29 \%$ incidence reported by Davis et al. ${ }^{27}$ In all analyses, the most common errors leading to missed diagnosis were the failure to obtain an adequate series of C-spine $x$-rays and misinterpretation of the $x$ rays which were obtained. Failure to initiate and maintain spinal immobilization was deemed to be the final common pathway for secondary injury.

A classification system of AOD based on the direction of displacement of the occiput to the atlas was devised by Traynelis et al. ${ }^{28}$ (Figure 4). In type I, the occiput moves anteriorly with respect to the atlas. In type II, there is a longitudinal separation of the occiput and atlas. Type III indicates that the occiput has moved posteriorly with respect to the atlas. Dickman $e t a l$. have also noted the potential for a rotatory dislocation, not originally described by Traynelis. ${ }^{29}$ It is not uncommon to have more than one translational abnormality on radiographic evaluation. Our patient had a predominant type II injury with concurrent evidence of an anterior dislocation (type I). Often, the displacement is subtle, and retropharyngeal swelling due to hematoma accumulation may be the first insight into the diagnosis in an otherwise normal radiograph.

Because lateral cervical spine radiographs have often been inconclusive in making the diagnosis of AOD, several methods of interpreting the normal atlanto-axial-occipital alignment and distances have been developed. Wholey et al. ascertained that the distance between the tip of the dens and the overlying 
basion in adults averages $5 \mathrm{~mm}$; any distance greater than this was considered abnormal. ${ }^{30}$ Dublin et al. examined the distances between the anterior arch of the atlas and the posterior aspect of the mandible, and from the anterior dens to the posterior mandible. ${ }^{31}$ In all of their cases of AOD, these measured distances exceeded the normal ranges. Powers compared the ratio of distances from the most anterior portion of the foramen magnum (the basion, B) to the posterior arch of the atlas (C), with the distance from the most posterior portion of the foramen magnum (the opisthion, 0) to the anterior arch of the atlas (A) $[$ Power's ratio $=\mathrm{B}-\mathrm{C} / \mathrm{O}-\mathrm{A}] .{ }^{23} \mathrm{~A}$ Power's ratio $>1$ was found in fewer than $1 \%$ of the normal population, and was used as their threshold for diagnosing this condition. Kaufman et al. proposed measuring the actual distance between the occipital condyle and the condylar facet of $\mathrm{Cl}$ on the lateral plain film for radiographic documentation of an atlanto-occipital dislocation. ${ }^{32}$ Each of these methods has shortcomings related to magnification factors, variation with flexion, extension, and rotation of the neck, identification of anatomic landmarks, as well as questionable validity in congenital anomalies of the atlanto-occipital region or concomitant fractures of the atlas. A combination of strategies rather than a single schema is usually employed in the radiological assessment.

CT offers an attractive alternative to plain radiography in the diagnosis and management of an atlantooccipital dislocation. CT scanning allows accurate assessment of osseous and soft-tissue anatomy in this region. ${ }^{25}$ Intracranial lesions are better detected and evaluated with this modality. Excessive repositioning of the patient, which may be necessary with plain tomography, is avoided, as multiple views of the cranio-cervical region may be obtained with the patient in the supine position. Although magnetic resonance imaging has not been used extensively for the evaluation of this injury, it will demonstrate spinal cord compression and brain parenchymal injury better than CT or plain radiographs. ${ }^{25}$

\section{Management issues in patients with $A O D$}

There is a spectrum of presentations among patients with AOD. The range spans patients who may be awake, alert, co-operative and neurologically intact to those in cardiopulmonary arrest with flaccid paralysis. There may be no other injuries or the patient may have suffered extensive trauma in addition to the AOD. In patients who initially present with no indication for airway intervention, ongoing surveillance of airway and respiratory status are necessary as deterioration in patient condition leading to respiratory insufficiency and arrest are commonly reported. This deterioration may be reversible and may be attributable to either increasing edema resulting from cord contusion or alternatively to vascular compromise. Maintenance of spinal immobilization is necessary to reduce the likelihood of deterioration resulting from loss of cranio-cervical alignment.

Patients who initially present with an indication for airway intervention will typically do so because of severe respiratory insufficiency or arrest. They obviously have a grossly unstable cervical spine. They will also commonly have injuries to the face or airway which may complicate airway interventions.

Continuous, in-line immobilization, performed without traction forces should be maintained at all times. Although Lennarson et al. have recently reported that MILI does not eliminate movement during intubation in the presence of posterior injury nor complete ligamentous disruption, the movements allowed are within physiological limits. ${ }^{10,11}$ Majernick demonstrated that MILI reduced total spinal movement during the process of intubation and that movement was not reduced to a similar degree by either soft or hard collars. ${ }^{33}$ Average movement at the atlanto-occipital joint during intubation was $4 \mathrm{~mm}$ (range 2-7 mm) without in-line immobilization and $1.75 \mathrm{~mm}$ (range 1-3 mm) with immobilization. Avoiding traction forces during the application of MILI may be particularly important when there is a serious ligamentous injury. Lennarson noted excess distraction at the site of a complete ligamentous injury, when traction forces were applied for the purposes of spinal stabilization during direct laryngoscopy. ${ }^{11}$ Similarly, Kaufmann demonstrated that in-line traction applied for the purposes of radiographic evaluation resulted in spinal column lengthening and distraction at the site of injury in four patients with unstable cervical spine fractures and ligamentous disruptions. ${ }^{34}$ Bivins studied the effect of inline traction during orotracheal intubation in four victims of blunt traumatic arrest with unstable spinal injuries. ${ }^{35}$ Traction applied to reduce subluxation at the sight of injury, resulted both in distraction and posterior subluxation at the fracture site. Axial traction during laryngoscopy and intubation resulted in less subluxation than when intubation was performed without traction but any benefit from the reduced subluxation may have been negated by the increased distraction at the site of injury.

The use of MILI rather than other immobilization techniques may also have lesser impact on the ease of airway management. Heath examined the effect on laryngoscopy of two different cervical spine immobilization techniques in 50 patients. ${ }^{36}$ First, the cervical spine was 
immobilized in a rigid collar with tape across the forehead and sandbags on either side of the neck, and subsequently with an assistant providing MILI. There was a poor view on laryngoscopy (grade 3 or 4 ) in $64 \%$ of patients when immobilized in a collar, tape and sandbags compared to $22 \%$ of patients undergoing MILI. In $56 \%$ of patients the view of the larynx improved by one grade and in $10 \%$ the view improved by two grades when MILI was substituted for the collar, tape and sandbags. Mouth opening was significantly reduced when patients were wearing cervical collars and this was the main factor contributing to the increased difficulty of laryngoscopy in this particular form of cervical spine immobilization. Gerling et al. conducted an analogous study using a cadaver model with a C5-6 destabilization and arrived at similar findings. ${ }^{37}$ MILI allowed less spinal movement than did cervical collar immobilization during laryngoscopy and intubation but was associated with improved laryngeal visualization.

Hastings measured the degree of head extension required to expose the arytenoid cartilages and glottis and determined whether MILI alters this. ${ }^{38}$ The subjects were anesthetized patients with normal cervical spines and Mallampati I views. Without stabilization, arytenoid cartilage exposure and the best view of the glottis was achieved with $10^{\circ} \pm 5^{\circ}$ (mean $\pm \mathrm{SD}$ ) and $15^{\circ} \pm 6^{\circ}$ of head extension, respectively. Head immobilization reduced extension angles $4 \pm 5$ for arytenoid exposure and $5^{\circ} \pm 6^{\circ}$ for best view compared with no stabilization. The use of MILI significantly reduced the amount of head extension that was necessary for laryngoscopy.

Although MILI seems to have the least impact of all immobilization techniques on airway management, it does make direct laryngoscopy more difficult than if no immobilizing forces are being used. Wood studied the effect of cervical stabilization maneuvers on the view obtained at laryngoscopy in 78 uninjured, elective surgical patients and concluded that cervical immobilization typically worsened laryngoscopic view. ${ }^{39}$ Anterior laryngeal or cricoid pressure often improved the view of the larynx when the neck was immobilized and Donaldson has reported that application of cricoid pressure does not result in movement in an injured upper cervical spine. ${ }^{7}$

It is recommended that MILI be used for spinal immobilization during tracheal intubation. It is also advisable to remove the anterior portion of the cervical collar during airway interventions; not only will airway management be facilitated but spinal movement will also be reduced if MILI is substituted at this time for the cervical collar.

The most appropriate technique for performing tracheal intubation in patients with cervical spine injury continues to be debated. Techniques for tracheal intubation which minimize neck movement (light stylet, rigid or flexible fibreoptic scopes) offer an advantage in terms of reduction of spinal movement during airway interventions and their use is encouraged. For example, movement during intubation with the Augustine Guide, a device enabling blind oral intubation with the patient's head and neck maintained in the neutral position, was compared with that measured during direct laryngoscopy ${ }^{40}$ The tracheas of 12 patients (Mallampati I and II) without a cervical injury, were intubated using the Augustine Guide and afterwards by direct laryngoscopy. Both procedures were viewed radiographically and extension in the upper cervical spine was determined at the point of the maximum excursion. By evaluating the joints occiput-C3 together as a functional unit, blind oral intubation caused less extension compared to direct laryngoscopy.

There are no outcome data which would suggest better outcomes with any particular technique. Rather, it is likely that prudent, cautious care and maintenance of spinal immobilization are more important factors in limiting the risk of secondary neurological injury than any particular technique. All airway maneuvers will result in some degree of neck movement, both, in general and specifically at the sites of injury. The amounts of movement are small, are reduced by in-line immobilization and both the available data and the accumulated experience would support the conclusion that they are unlikely to result in neurological injury provided that reasonable care is taken during airway interventions.

McLeod and Calder have recently reviewed the use of the direct laryngoscope in patients with spinal injury or pathology. ${ }^{41}$ They acknowledge six case reports, dealing with ten patients, in which it was alleged that direct laryngoscopy likely contributed to a neurological injury. With the possible exception of one case, they concluded after review of the reports, that it was unlikely that the use of the direct laryngoscope was the cause of the myelopathies reported. Hastings and Kelley reported the case of a man with an unrecognized cervical spinal injury who became quadriplegic after bagmask ventilation, direct laryngoscopy and cricothyrotomy. ${ }^{42}$ The case was that of a 65 -yr-old man admitted to hospital after a motor-vehicle accident. Despite complaining of neck pain and exhibiting left arm weakness, cervical spine injury was not effectively ruled out, nor was spinal immobilization maintained. His condition deteriorated some hours subsequently and after repeated, failed attempts at direct laryngoscopy without spinal immobilization, he underwent 
cricothyrotomy. The next day, it was noted that he was not moving his legs. A review of the original cervical spine $x$-ray demonstrated a widened disc space at C6-7 suggesting disruption of the anterior longitudinal ligament. CT scanning confirmed that finding as well as noting congenital spinal stenosis from $\mathrm{C} 3-\mathrm{C} 7$, osteophyte fragments in the spinal canal at $\mathrm{C} 6$, a fracture of the C6-C7 facet joint, a C7 laminar fracture and a C6 spinous fracture. At no time from admission until the occurrence of his neurological deterioration was his spine immobilized. Liang et al. have also reported the case of a male motor- vehicle accident victim with a suspected cervical spine injury who was left quadriplegic after airway management. ${ }^{43}$ Despite the evidence of a neurological injury (limited movement in both upper extremities) repeated and failed attempts were made at nasal (five attempts) and then oral intubation with a direct laryngoscopy (five attempts). The last three attempts at oral intubation were made after removal of the cervical collar but in-line-immobilization was not maintained. The trachea was eventually intubated via a surgical airway.

In patients with traumatized and distorted facial and upper airway anatomy, the direct laryngoscope may be preferred as it allows for wider survey and assessment of the traumatized field, with retrieval of upper airway debris or foreign bodies. This, despite the fact that more spinal movement might result with the use of the direct laryngoscope compared with the indirect alternatives. A second source of light in addition to the laryngoscope may be useful in this setting and mounting the endotracheal tube on a light stylet will provide for this. Additionally, ensuring adequate suction capability by taping two Yankauer suctions together will provide for this need. Tracheostomy should be considered early if patients present with facial injuries that are so extensive as to significantly compromise airway integrity and interventions. Cricothyrotomy resulted in a small $(1-2 \mathrm{~mm})$ but clinically insignificant amount of subluxation at the site of injury in a model of spinal injury using a C5-6 destabilization and, if indicated, should not be withheld for fear of worsening neurological injury. ${ }^{44}$ Tracheal disruption has also been reported after AOD and a high index of suspicion should be maintained. ${ }^{45}$ There should be a low threshold for early endoscopic evaluation of the subglottic airway if there is evidence of a tracheal air leak after intubation.

There is insufficient data to define a role for the LMA in these patients. The magnitude of spinal movements caused by manipulations of LMA in these patients is not great but high pressures against the upper cervical spine have been measured. ${ }^{12,13}$
Regurgitation and aspiration are a major risk and the security of the airway is not reliably ensured with a LMA in this scenario.

Many of these injuries result in translational malalignment in addition to longitudinal distraction of the occipito-cervical complex and reduction maneuvers may be required to achieve joint re-alignment. There is controversy regarding the use of longitudinal traction in the early management of this injury. Frequent reports of distraction at the site of injury with subsequent neurological deterioration during traction encourage the increasing use of the halo fixator for short-term immobilization. ${ }^{46}$ Once adequate reduction is accomplished, prompt temporary immobilization may be obtained through the application of the halo fixator. Although re-displacement has been reported in the halo device before definitive osseous fusion, this apparatus seems to provide the most secure method of early immobilization compared with other conventional cervical orthoses. The halo may also be used for long-term stabilization. However, long-term survivors with persistent ligamentous instability remain a concern, and posterior occipito-axial fusion is recommended as the definitive treatment. ${ }^{46}$

Patients who survive traumatic AOD and present to hospital are uncommon. However, of those who do, both intact survival and survival with limited neurological sequelae do occur and are not uncommon. Meticulous airway care with maintenance of alignment and provision of continuous cervical immobilization are an integral component of care in these patients.

\section{References}

1 Hensinger RN. Congenital anomalies of the atlantoaxial joint. In: The Cervical Spine Research Society Editorial Committee (Eds.). The Cervical Spine, $2^{\text {nd }}$ ed. Philadelphia: JB Lippincott, 1989: 236-43.

2 Steel $\mathrm{HH}$. Anatomical and mechanical considerations of the atlanto-axial articulations. J Bone Joint Surg 1968; 50: 1481-90.

3 Jofe $M H$, White AA, Panjabi MM. Clinically relevant kinematics of the cervical spine. In: The Cervical Spine Research Society Editorial Committee (Eds.). The Cervical Spine, $2^{\text {nd }}$ ed. Philadelphia: JB Lippincott, 1989: 57-69.

4 White AA III, Johnson RM, Panjabi MM, Southwick $W O$. Biomechanical analysis of clinical stability in the cervical spine. Clin Orthop 1975; 109: 85-95.

5 White AA III, Panjabi MM. Clinical Biomechanics of the Spine, $2^{\text {nd }}$ ed. Philadelphia: JB Lippincott, 1990: 314-7.

6 Sawin PD, Todd MM, Traynelis VC, et al. Cervical spine motion with direct laryngoscopy and orotracheal 
intubation. An in vivo cinefluoroscopic study of subjects without cervical abnormality. Anesthesiology 1996; 85: 26-36.

7 Horton WA, Faby L, Charters P. Disposition of the cervical vertebrae, atlanto-axial joint, hyoid and mandible during x-ray laryngoscopy. Br J Anaesth 1989; 63: 435-8.

8 Donaldson WF III, Heil BV, Donaldson VP, Silvaggio $V J$. The effect of airway maneuvers on the unstable C1-C2 segment. A cadaver study. Spine 1997; 22: 1215-8.

9 Aprahamian C, Thompson BM, Finger WA, Darin JC. Experimental cervical spine injury model: evaluation of airway management and splinting techniques. Ann Emerg Med 1984; 13: 584-7.

10 Lennarson PJ, Smith D, Todd MM, et al. Segmental cervical spine motion during orotracheal intubation of the intact and injured spine with and without external stabilization. J Neurosurg (Spine 2) 2000; 92: 201-6.

11 Lennarson PJ, Smith DW, Sawin PD, et al. Cervical spinal motion during intubation: efficacy of stabilization maneuvers in the setting of complete segmental instability. J Neurosurg (Spine 2) 2001; 94: 265-70.

12 Kihara S, Watanabe S, Brimacombe J, Taguchi N, Yaguchi $\Upsilon$, Yamasaki $\Upsilon$. Segmental cervical spine movement with the intubating laryngeal mask during manual in-line stabilization in patients with cervical pathology undergoing cervical spine surgery. Anesth Analg 2000; 91: 195-200.

13 Keller C, Brimacombe J, Keller K. Pressures exerted against the cervical vertebrae by the standard and intubating laryngeal mask airways: a randomized, controlled, cross-over study in fresh cadavers. Anesth Analg 1999; 89: 1296-1300.

14 Lee C, Woodring JH, Walsh JW. Carotid and vertebral artery injury in survivors of atlanto-occipital dislocation: case reports and literature review. J Trauma 1991; 31: 401-7.

15 Alker GJ Jr, Oh YS, Leslie EV, Lehotay J, Panaro VA, Eschner EG. Postmortem radiology of head and neck injuries in fatal traffic accidents. Radiology 1975; 114: 611-7.

16 Bucholz RW, Burkhead WZ, Graham W, Petty C. Occult cervical spine injuries in fatal traffic accidents. J Trauma 1979; 19: 768-71.

17 Davis D, Bohlman H, Walker AE, Fisher R, Robinson $R$. The pathological findings in fatal craniospinal injuries. J Neurosurg 1971; 34: 603-13.

18 Chiu WC, Haan JM, Cushing BM, Kramer ME, Scalea $T M$. Ligamentous injuries of the cervical spine in unreliable blunt trauma patients: incidence, evaluation, and outcome. J Trauma 2001; 50: 457-64.

19 Werne S. Studies in spontaneous atlas dislocation. Acta
Orthop Scand 1957; 23(suppl): 1-150.

20 Bailey H, Perez N, Blank-Reid C, Kaplan LJ. Atlantooccipital dislocation: an unusual lethal airbag injury. J Emerg Med 2000; 18: 215-9.

21 Gabrielsen TO, Maxwell JA. Traumatic atlanto-occipital dislocation with case report of a patient who survived. Radiology 1966; 97: 624-9.

22 Evarts CM. Traumatic occipito-atlantal dislocation. Report of a case with survival. J Bone Joint Surg 1970; 52-A: 1653-60.

23 Powers B, Miller MD, Kramer RS, Martinez S, Gehweiler JA Jr. Traumatic anterior atlanto-occipital dislocation. Neurosurgery 1979; 4: 12-7.

24 Przybylski GJ, Clyde BL, Fitz CR. Craniocervical junction subarachnoid hemorrhage associated with atlantooccipital dislocation. Spine 1996: 21: 1761-8.

25 Ferrera PC, Bartfield JM. Traumatic atlanto-occipital dislocation: a potentially survivable injury. Am J Emerg Med 1996; 14: 291-6.

26 Reid DC, Henderson R, Saboe L, Miller JDR. Etiology and clinical course of missed spine fractures. J Trauma 1987; 27: 980-6.

27 Davis JW, Phreaner DL, Hoyt DB, Mackersie RC. The etiology of missed cervical spine injuries. J Trauma 1993; 34: 342-6.

28 Traynelis VC, Marano GD, Dunker RO, Kaufman HH. Traumatic atlanto-occipital dislocation. Case report. J Neurosurg 1986; 65: 863-70.

29 Dickman CA, Papadopoulos SM, Sonntag VKH, Spetzler RF, Rekate HL, Drabier J. Traumatic occipitoatlantal dislocations. J Spinal Disord 1993; 6: 300-13.

30 Wholey MH, Bruwer AJ, Baker HL Jr. The lateral roentgenogram of the neck (with comments on the atlanto-odontoid-basion relationship). Radiology 1958; 71: 350-6.

31 Dublin AB, Marks WM, Weinstock D, Newton TH. Traumatic dislocation of the atlanto-occipital articulation (AOA) with short-term survival. With a radiographic method of measuring the AOA. J Neurosurg 1980; 52: 541-6.

32 Kaufman RA, Dunbar JS, Botsford JA, McLaurin RL. Traumatic longitudinal atlanto-occipital distraction injuries in children. AJNR 1982; 3: 415-9.

33 Majernick TG, Bieniek R, Houston JB, Hughes HG. Cervical spine movement during orotracheal intubation. Ann Emerg Med 1986; 15: 417-20.

34 Kaufman HH, Harris JH Jr, Spencer JA, Kopanisky $D R$. Danger of traction during radiography for cervical trauma (Letter). JAMA 1982; 247: 2369.

35 Bivins HG, Ford S, Bezmalinovic Z, Price HM, Williams $J L$. The effect of axial traction during orotracheal intubation of the trauma victim with an unstable cervical spine. Ann Emerg Med 1988; 17: 25-9. 
36 Heath KJ. The effect on laryngoscopy of different cervical spine immobilisation techniques. Anaesthesia 1994; 49: 843-5.

37 Gerling MC, Davis DP, Hamilton RS, et al. Effects of cervical spine immobilization technique and laryngoscope blade selection on an unstable cervical spine in a cadaver model of intubation. Ann Emerg Med 2000; 36: 293-300.

38 Hastings $R H$, Wood PR. Head extension and laryngeal view during laryngoscopy with cervical spine stabilization maneuvers. Anesthesiology 1994; 80: 825-31.

39 Wood PR, Dresner M, Hayden Smith J, Kumar CM, Lawler PGP. Direct laryngoscopy and cervical spine stabilisation (Letter). Anaesthesia 1994; 49: 77-8.

40 Fitzgerald RD, Krafft P, Skrbensky G, et al. Excursions of the cervical spine during tracheal intubation: blind oral intubation compared with direct laryngoscopy. Anaesthesia 1994; 49: 111-5.

41 McLeod AD, Calder I. Spinal cord injury and direct laryngoscopy - the legend lives on (Editorial I). Br J Anaesth 2000; 84: 705-8.

42 Hastings RH, Kelley SD. Neurologic deterioration associated with airway management in a cervical spineinjured patient. Anesthesiology 1993; 78: 580-3.

43 Liang BA, Cheng $M A$, Tempelhoff $R$. Efforts at intubation: cervical injury in an emergency circumstance? J Clin Anesth 1999; 11: 349-52.

44 Gerling MC, Davis, DP, Hamilton RS, et al. Effect of surgical cricothyrotomy on the unstable cervical spine in a cadaver model of intubation. J Emerg Med 2001; 20: $1-5$.

45 Palmer MT, Turney SZ. Tracheal rupture and atlantooccipital dislocation: case report. J Trauma 1994; 37 : 314-7.

46 Ahuja A, Glasauer FE, Alker GJ Jr, Klein DM. Radiology in survivors of traumatic atlanto-occipital dislocation. Surg Neurol 1994; 41: 112-8. 